\title{
Improving Early Diagnosis of Rare Diseases Using Natural Language Processing in Unstructured Medical Records: An Illustration From Dravet Syndrome
}

\section{Tommaso Lo Barco}

University of Verona: Universita degli Studi di Verona https://orcid.org/0000-0002-3103-230X

Mathieu Kuchenbuch

Université de Paris

\section{Nicolas Garcelon}

Institute Imagine Institute of Genetic Diseases: Institut Imagine Institut des Maladies Genetiques

\section{Antoine Neuraz}

Fondation Imagine: Institut Imagine Institut des Maladies Genetiques

Rima Nabbout ( $\square$ rimanabbout@yahoo.com )

Department of Pediatric Neurology, Necker-Enfants Malades Hospital, Centre de Référence Épilepsies Rares, member of ERN EPICARE, Université de Paris, Paris, France. https://orcid.org/0000-0001-5877-4074

\section{Research}

Keywords: Data mining, Natural Language Processing, Dravet Syndrome, Rare Diseases, Early diagnosis

Posted Date: January 20th, 2021

DOI: https://doi.org/10.21203/rs.3.rs-149382/v1

License: @ (i) This work is licensed under a Creative Commons Attribution 4.0 International License. Read Full License

Version of Record: A version of this preprint was published at Orphanet Journal of Rare Diseases on July 13th, 2021. See the published version at https://doi.org/10.1186/s13023-021-01936-9. 


\section{Abstract}

\section{Background}

The growing use of Electronic Health Records (EHRs) is promoting the application of data mining in healthcare. A promising use of big data in this field is to develop models to support early diagnosis and to establish natural history.

Dravet Syndrome (DS) is a rare Developmental and Epileptic Encephalopathy that commonly initiates in the first year of life with febrile seizures (FS). Age at diagnosis is often delayed after two years, as it is difficult to differentiate DS at onset from FS.

We aimed to explore if some clinical terms (concepts) are significantly more used in the electronic narrative medical reports of individuals with DS before the age of two years compared to those of individuals with FS. These concepts would allow an earlier detection of patients with DS resulting in an earlier orientation toward expert centers that can provide early diagnosis and care.

\section{Methods}

Data were collected from the Necker Enfants Malades Hospital using a document-based data warehouse, $D r$ Warehouse, which employs Natural Language Processing, a computer technology consisting in processing written information. Using Unified Medical Language System Meta-thesaurus, phenotype concepts can be recognized in medical reports.

We selected individuals with DS (DS Cohort) and individuals with FS (FS Cohort) with confirmed diagnosis after the age of four years. A phenome-wide analysis was performed evaluating the statistical associations between the phenotypes of DS and FS, based on concepts found in the reports produced before two years and using a series of logistic regressions.

\section{$\underline{\text { Results }}$}

We found significative higher representation of concepts related to seizures' phenotype distinguishing DS from FS in the first phases, namely the major recurrence of complex febrile convulsions (long-lasting and/or with focal signs) and other seizure-types. Some typical early onset non-seizure concepts also emerged, in relation to neurodevelopment and gait disorders.

\section{$\underline{\text { Conclusions }}$}

Narrative medical reports of individuals younger than two years with FS contain specific concepts linked to DS diagnosis, which can be automatically detected by software exploiting NLP. This approach could represent an innovative and sustainable methodology to decrease time of diagnosis of DS and could be transposed to other rare diseases.

\section{Objectives}


Electronic health records (EHRs) contain healthcare data of individuals and population electronically-stored in a digital format.(1) In the last decade, the use of EHRs has become part of routine care across the majority of developed countries.(2)

Through data mining techniques, this growing use of EHRs is allowing the development of predictive models aimed to individuate high risk patients and support prevention initiatives. $(3,4)$ As well, models to support diagnosis and treatment of rare diseases are emerging. $(5,6)$

EHRs consist of structured and unstructured data. Structured data are produced through constrained choices (drop-down menus, check boxes and pre-filled templates as in registries), whereas unstructured clinical data exist in the form of free text narratives and are often used in clinical care for medical reports.(7) Combining Natural Language Processing (NLP) technology and UMLS (Unified Medical Language System), providers' notes and narratives can be converted into structured, standardized formats, usable for data mining.(8-10)

Dravet Syndrome (DS) is a rare disorder, with a worldwide incidence between 1/40,000 and 1/15,700.(11) DS is a genetic developmental and epileptic encephalopathy with onset in first year of life, characterized at onset by febrile seizures and convulsive status epilepticus in otherwise healthy infants.(12) Starting by the second year, individuals present multiple seizure types (clonic, tonic-clonic, motor and non-motor onset focal seizures, myoclonic, atypical absences), that are often drug resistant, with developmental slowing leading to definite cognitive impairment.(13) Diagnosis is easier after the age of two as more pathognomonic seizure types and other symptoms are present from this age. Genetic testing shows a pathogenic variant in SCN1A in over 85\% of cases reinforcing the diagnosis suspicion, but this testing might take months and is not available for all individuals with suspected DS.(14) However there is a need for early diagnosis in order to avoid worsening therapies and to establish best therapy protocol as seizure control might be partly related to cognitive improvement and a better quality of life.(15)

Early diagnosis of individuals with DS is often delayed as it is difficult to differentiate at onset from Febrile Seizures (FS).(16) These two conditions present substantial clinical differences, leading to exclude one on other diagnosis but might be overlapping at onset. Even if physician awareness of Dravet syndrome has markedly improved in last decades,(17) time to diagnosis is still over two years,(18) and it remains underdiagnosed in adult population and in developing countries. $(19,20)$

Using data mining, we analysed clinical reports produced before the age of two years for individuals with confirmed DS and FS with the aim of identifying specific terms (concepts) allowing early DS suspicion and reducing diagnosis delay. We then explored the differences between the concepts in the reports of two subgroups of individuals with DS: patients with suspected diagnosis before the age of 2 years and patients for whom diagnosis was suspected after the age of two.

\section{Materials And Methods}

Data were collected from Necker Enfants Malades Hospital, a paediatric University hospital belonging to the Assistance Publique Hopitaux de Paris group (400 paediatric beds, 200 adult beds), which is a national and European reference center for rare and undiagnosed diseases, including the reference a centre for rare epilepsies. 
DrWarehouse $^{\mathrm{O}}(21)(\mathrm{DrWH})$ is a document-based open-source clinical data warehouse oriented toward free text, containing more than 4.5 million clinical free-text documents produced at Necker Hospital from 2009, for more than 465,000 individuals and more than 20 hospital departments. DrWH uses UMLS Metathesaurus to recognize phenotype concepts inside narrative medical reports. In this manuscript, the word "concepts" will refer to phenotypes extracted automatically from hospital reports, without a priori, by using a UMLS subset of 20,000 phenotypic words or expressions.

By using the appropriate research field in DrWarehouse ${ }^{\circ}$, we found all individuals who presented in their reports the word "Dravet" or "Severe Myoclonic Epilepsy of Infancy" at least in one clinical document. Among them, only those with final diagnosis of DS after the age of four years have been selected. From this cohort, we retained only those individuals with at least one clinical report before the age of two years, who constituted the "Dravet Syndrome Cohort" (DS Cohort).

Subsequently, we searched in the data warehouse all individuals whose medical reports produced before the age of two presented the words "seizure" or "convulsion" near to the words "fever" or "febrile", using the string "NEAR((fever OR febrile,seizure\% OR Convulsion\%),5,true). Among them, we excluded individuals of DS Cohort and those in which febrile seizures was a symptom of a more complex condition (infections involving the central nervous system, other encephalopathies, structural brain injury, detected genetic or metabolic pathologies, or epilepsies). Individuals in this remaining group with a diagnosis confirmation was obtained after the age of four based on the EHRs or by telephone, interviewing the family of the individuals, made up the "Febrile Seizures Cohort" (FS Cohort) (Figure 1).

The phenome-wide scan consists in comparing the distribution of phenotypes between two groups (cases and controls) and estimates the association between the phenotypes and the groups. These associations are assessed sequentially. $(22,23)$ We evaluated the statistical associations between the phenotypes and the cohorts DS and FS, using a series of multivariate logistic regressions adjusted on gender and age. For the analysis, we used concepts found in clinical reports with a minimum number of occurrences of three individuals, excluding negations and those associated to family members. The $p$-values were corrected for multiple testing using a false discovery rate (FDR) methodology.

We also compared the phenotype differences in the DS Cohort between the subgroup where diagnosis of DS was confirmed or suspected before the age of two years, and the subgroup where DS diagnosis was not reported.

\section{Results}

"Dravet Syndrome Cohort" (DS Cohort)

The term "Dravet" and/or "severe myoclonic epilepsy of infancy" appeared in 305 individuals present in the warehouse: 194 of them had a final diagnosis of DS in the last document on the database, 51 had at least one document produced under the age of two years. All had a clinical and genetic diagnosis of DS. These individuals constituted the DS Cohort. 
DS cohort included 28 males and 23 females. The mean age at first seizure was 5,5 months ( $\min 2-\max$ 12). The average age of the first produced document was 1,05 years, median is 1,15 ( $\min 0,25$ - $\max 1,98)$. The average length of the follow-up of these individuals was 5,68 years, median 4,98 ( $\min 3,75-\max 13,42)$.

In order to compare this population with a population with FS at the same age, documents produced exclusively before two years was selected, for a total of 318 documents (mean: 6,24; median: 3 for each individual). 3484 concepts were extracted from the abovementioned documents (mean: 10,9 per document), 454 of which were unique concepts. Concepts present in almost $10 \%$ of the population are listed in a decreasing order in the Table 1.

"Febrile Seizure Cohort" (FS Cohort)

The research of the words "seizure" or "convulsion" in individuals' reports close to the words "febrile" or "fever", limited to documents produced by the first two years of life and excluding individuals of DS Cohort, led to 256 subjects. After exclusion of other aetiologies, we included all 53 subjects with a diagnosis of febrile seizures confirmed after age four in the FS cohort.

This cohort was constituted of 17 females and 36 males. The mean age of the first document produced was 1,18 years, while median was $1,3(\min 0,30$ - $\max 1,96)$. The mean duration of follow-up was 4,20 years, median 4,02 ( $\min 3,70-\max 5,57)$. The mean age at first seizure was 12,4 months ( $\min 4-\max 21)$ with 1 individual having an onset before six months and 23 before 12 months.

In order to compare phenotypes of FS Cohort with DS Cohort at the same age (before the age of two years), documents produced exclusively before two years were selected, for a total of 233 documents (mean 4,4; median 3 for each individual). From these, 2053 concepts have been extrapolated (mean 8,8 concepts per document), 303 of which were unique concepts.

The concepts present in at least $10 \%$ of individuals are shown in Table 1.

Comparison of DS and FS cohorts

DS cohort was constituted of $54 \%$ of males and $46 \%$ of females, while a significative difference between the two genders existed in the FS cohort, constituted of $68 \%$ of males and $32 \%$ of females.

The different length of follow-up among the two cohorts, shows the complexity of the condition of individuals with DS (mean 3,99 years, median 3,11), compared to individuals with FS (mean 1,82 years, median 1,37 years) that request a shorter follow-up. Indeed the clinics at Necker hospital often stop when the diagnosis of FS is confirmed and they are usually referred back to their paediatrician or general physician.

The mean number of documents per individual produced in the same age range (0-2 years), was higher in the population with DS $(6,2$ vs 4,4$)$, as well as the mean number of concepts extrapolated per document $(10,9 \mathrm{vs}$ $8,8)$.

The phenome-wide comparison of both cohorts showed a significantly different representation of some concepts which are listed in Table 2. 
DS Cohort: diagnosis/suspected diagnosis received versus not received before two years

Within DS cohort, we distinguished two sub-populations: the first, composed of 36 subjects ( $72 \%)$, in which the concept "Dravet Syndrome" was reported in the clinical reports before the age of two years. The second included 15 subjects (28\%) who did not present the term "Dravet" neither "SCN1A", meaning that the diagnosis was not done/suspected by the age of two years. The absence of DS suspicion cannot be confirmed based on these data, but it is also possible that no suspicion was raised as individuals did not have any genetic testing, a strict procedure in our institution when DS is suspected. In one individual of this group, the term "myoclonic epilepsy" was present in a report. He was excluded from this part of analysis.

The mean age at first seizure was 5,3 months ( $\min 2-\max 12)$ in the subpopulation that received a suspect/diagnosis within two years, and 6,1 months $(\min 2-\max 9)$ in the group without an early diagnosis.

We studied the different representation of the clinical concepts between these two sub-cohorts. Results show some differences among the phenotypes of these two subgroups (Table 3).

\section{Discussion}

This study shows that narrative medical reports produced before two years include several clinical concepts which are significantly associated with individuals with DS compared to FS, this latter condition representing the main differential diagnosis at the onset. These concepts are consistent with the main clinical findings constituting the criteria for differentiating DS from FS in first two years of life.

A series of these concepts refers to the different epileptic phenotype which distinguishes DS from FS at the early stages. Concept "Deviation" ( $p<0,01)$, which is found within sentences describing focal seizures, is indicative of the higher tendency of subjects with DS to present seizures with focal signs compared to those with FS. $(16,24,25)$ The increased frequency of concepts "Prolonged Seizures" $(p=0,05)$ and "Status epilepticus" $(p=0,07)$, proves the major trend of these subjects to experience long-lasting seizures, and "Sedation" $(p=0,02)$ reflects the high need of rescue medications to stop them, or the post-ictal phase of these long-lasting seizures or a longer post ictal period due to long-lasting seizures. $(13,26,27)$ Furthermore, some concepts related to characteristic DS seizure types were also significantly prevalent in the DS Cohort, as "Myoclonia" $(p=0,02)$ and "Clonic" $(p=0,02) .(16,28,29)$ Interestingly, the concept "Startle" $(p=0,07)$, which is mostly used in narrative reports to depict myoclonic seizure semiology, was higher in the DS Cohort.

Some important non-seizure concepts also emerged such as "Regression" $(p=0,03)$ and "Psychomotor delay" $(p=0,07)$, exclusively reported in the DS Cohort, reflecting the developmental impairment which is present in individuals with DS. $(25,30)$ In addition, "Ataxia" $(p=0,02)$ was significantly more reported DS Cohort, reflecting the peculiar gait disorder commonly observed in individuals with DS, and representing an early motor-marker of this condition. $(29,31)$

Interestingly, the concept "febrile seizures" was found with significant higher frequency in the FS Cohort $(p=0,01)$ probably because it was used for a "diagnostic" purpose in the clinical reports. 
There were some trends for other concepts, but they did not reach statistical difference. For example "hemiparesis" ( $\mathrm{OR}=4,6)$, that often occur after long-lasting hemiclonic seizures that are typical of DS. $(16,28,32)$ "Photosensitivity" $(O R=4,6)$, that can be early reported in one third of individuals with DS and its recognition can add to the criteria of a positive diagnosis. $(33,34)$ "Pyramidal syndrome" $(O R=4,6)$, was a possible neurological findings at the first year of the disease, in addition to the onset of motor delay.(33)

The study was carried out in a tertiary epilepsy center, so it is plausible that some words have been chosen as a consequence of the clinical suspicion of Dravet Syndrome by highly experienced specialist in epileptology (e.g. "myoclonia", "ataxia"). Anyway, some documents were reported in some instances by physicians with no high expertise in epilepsy (e.g. emergency care or intensive care physicians), emphasizing the uniformity of expressions used for reporting disease and individuals description, and suggesting that most of key-concepts may have also been found into non-specialists medical reports (e.g. "deviation", "prolonged seizures", "startle").

Several studies shows a substantial worldwide issue of diagnostic delay of DS, with a mean age at diagnosis that is usually over two years, resulting in "unnecessary, costly, and, at times, invasive testing, and use of ineffective therapies, which can exacerbate seizures, increase the risk of status epilepticus, and worsen cognitive outcome".(17,35-37) Moreover, DS is certainly less recognized in adult population and in developing countries. $(19,20)$

Computer-based models using EHRs able to suggest diagnosis/avoid misdiagnosis are gaining ground. $(3,38)$ These models are mostly based on structured data, as image-based or laboratory data. $(39,40)$ Recently, more complex models of artificial intelligence are emerging, which are able to elaborate diagnosis by extracting clinically relevant information from unstructured data in EHRs.(41)

On the basis of our findings, further extensive studies might focus on elaborating a specific computer algorithm which combines significative concepts and their age of appearance within narrative specialists and non-specialists reports, in order to automatically produce an alert signal suggesting possible diagnosis of DS.

Some results of our analysis set out some insights. For example, the major incidence of concept "pneumonia" $(p=0,03)$ in DS Cohort compared to FS Cohort appears to be relevant, since it can represent both a facilitator and a complication of status epilepticus.(42) In addition, a number of concepts related to peri-ictal nosocomial and respiratory complications were found with higher frequency in reports of individuals with DS ("nosocomial infections", "acute respiratory insufficiency", "aspiration pneumonia", "FiO2", "stridor") (OR=4,6 for each concept) underlying that convulsive status epilepticus is an important life-threatening condition in this population. $(42,43)$

Furthermore, in this study the concept "Dravet Syndrome" was found in $72 \%$ of individuals of DS Cohort before the age of two years. This is concordant with the literature showing the early recognition of DS in France.(37)

Interestingly, some clinical concepts were found with higher frequency into the reports of individuals who received the diagnosis/suspicion of DS before two years: the "long-lasting seizure" concepts ("Status epilepticus", "Prolonged seizures", "Sedation"), the "myoclonic" concepts ("Myoclonia", "Startles"), the "drug 
resistance" concepts ("Ketogenic diet"), as well as "Ataxia", and "Photosensitivity". Although statistical significance was not reached (probably because of small numbers), these findings may support that these clinical concepts are the most DS diagnosis orienting. From this data, it can be assumed that subjects belonging to the sub-group who did not receive a diagnosis/suspicion within two years presented a less "typical" phenotype, explaining why more than two years were needed to make the diagnosis/suspicion. In these individuals, presenting "intermediate" features between individuals with only FS and those with DS presenting the "complete" clinical picture, median age at first seizure was significantly lower than in FS cohort (6,1 months vs 12,4 months), confirming once again that age at first seizure might be the strongest predictor of DS in infants who experience repeated febrile seizures.(24)

\section{Study Limitations}

Word sense disambiguation poses a challenge in extracting meaningful data from unstructured text. Clinical notes often contain terms or phrases that have more than one meaning,(8) or that need for a contextualisation to understand the real clinical meaning. For example, concepts "side" and "deviation" apparently do not link to a specific clinical feature, but in the narrative reports of individuals of both cohorts they were mostly used within the description of the seizure semeiology, thus referring to a focal seizure.

The presence of a clinical concept in a medical report does not necessary implies that the individual presents this clinical feature. For instance, the concept "spasms" that we found in five individuals of the DS Cohort, was used within the clinical description of paroxysmal motor events that could suggest epileptic spasms, but was not confirmed in any of them. The method used by Dr Warehouse automatically classifies concepts according to polarity (negation/affirmation) and the experiencer (patient/family). But there may still be errors in the classification. In addition, the classification does not take into account the notion of hypothesis.

In this study, the FS population presents some "atypical" features; for instance, the frequency of the concept "status epilepticus" in these subjects is higher than expected in terms of incidence in individuals with febrile seizures. $(44,45)$ This might be due to a preferential referral to university hospital of individuals with febrile long lasting seizures or febrile status epilepticus, as they might need further admission to ICU.

\section{Conclusion}

Narrative medical reports of individuals younger than two years with febrile seizures, contain different words depending if they have or will develop clinical phenotype of DS, or not. The elaboration of algorithm exploiting NLP on the basis of our work, could be useful to early individualize these individuals, in order to establish early diagnosis and adequate therapy that in some instances need to address them to expert epilepsy centres.

This methodology would represent an innovative, "cheap", transposable and sustainable methodology to reduce time of diagnosis for individuals with Dravet Syndrome and other rare conditions.

Some "key early symptoms" often identified by the patients/care givers and the non-expert physicians are merely linked to a given known disease causing diagnosis delay. Using these symptoms and signs as alerts and warning signs can help to address patients earlier to expert centres for a definite diagnosis. The future 
step is to validate the impact of the implementing of these "warnings" in the electronic health records on shortening the patient's odyssey to diagnosis and therapies.

\section{Declarations}

\section{Ethics approval and consent to participate}

This study had the approval of Necker Hospital ethic committee.

Consent for publication

Not applicable

Availability of data and materials

The datasets used and analysed during the current study are available from the corresponding author on reasonable request.

Competing interests

The authors declare that they have no competing interests

\section{Funding}

This work was supported by State funding from the Agence Nationale de la Recherche under "Investissements d'Avenir" program (ANR-10-IAHU-01) and the "Fondation Bettencourt Schueller" (RN).

\section{Authors' contributions}

TLB collected and interpreted data and drafted the work

MK collected and interpreted data

NG created the software used in the work and revised the manuscript

AN interpreted data and revised the manuscript

RN concepted and designed the work, supervised data collection and interpretation, revised the manuscript Acknowledgements

Not applicable

\section{References}

1. Gunter TD, Terry NP. The emergence of national electronic health record architectures in the United States and Australia: models, costs, and questions. J Med Internet Res. 2005 Mar 14;7(1):e3. 
2. Landi I, Glicksberg BS, Lee HC, Cherng S, Landi G, Danieletto M, et al. Deep representation learning of electronic health records to unlock patient stratification at scale. npj Digit Med. 2020;3:1-11.

3. Olivera P, Danese S, Jay N, Natoli G, Peyrin-Biroulet L. Big data in IBD: a look into the future. Nat Rev Gastroenterol Hepatol. 2019 May 1;16(5):312-21.

4. Bates DW, Saria S, Ohno-Machado L, Shah A, Escobar G. Big data in health care: Using analytics to identify and manage high-risk and high-cost patients. Health Aff. 2014;33(7):1123-31.

5. Shen F, Liu S, Wang Y, Wen A, Wang L, Liu H. Utilization of electronic medical records and biomedical literature to support the diagnosis of rare diseases using data fusion and collaborative filtering approaches. J Med Internet Res. 2018;20(10).

6. Southall NT, Natarajan M, Lau LPL, Jonker AH, Deprez B, Guilliams T, et al. The use or generation of biomedical data and existing medicines to discover and establish new treatments for patients with rare diseases-recommendations of the IRDiRC Data Mining and Repurposing Task Force. Orphanet J Rare Dis. $2019 ; 14(1)$.

7. Garcelon N, Neuraz A, Salomon R, Bahi-Buisson N, Amiel J, Picard C, et al. Next generation phenotyping using narrative reports in a rare disease clinical data warehouse. Orphanet J Rare Dis. 2018;13:85.

8. Townsend $\mathrm{H}$. Natural language processing and clinical outcomes: the promise and progress of NLP for improved care. J AHIMA. 2013;84:44-5.

9. Bodenreider O. The Unified Medical Language System (UMLS): integrating biomedical terminology. Nucleic Acids Res. 2004;32:D267-70.

10. Rindflesch TC, Fiszman M. The interaction of domain knowledge and linguistic structure in natural language processing: interpreting hypernymic propositions in biomedical text. J Biomed Inform. 2003;36(6):462-77.

11. Wu YW, Sullivan J, McDaniel SS, Meisler MH, Walsh EM, Li SX, et al. Incidence of dravet syndrome in a US population. Pediatrics. 2015;136(5):e1310-5.

12. Scheffer IE, Berkovic S, Capovilla G, Connolly MB, Guilhoto L, Hirsch E, et al. ILAE Classification of the Epilepsies Position Paper of the ILAE: Commission for Classification and Terminology. Epilepsia. 2017;58:512-21.

13. Dravet C. The core Dravet syndrome phenotype. Epilepsia. 2011;52(SUPPL. 2):3-9.

14. Hirose S, Scheffer IE, Marini C, De Jonghe P, Andermann E, Goldman AM, et al. SCN1A testing for epilepsy: Application in clinical practice. Epilepsia. 2013;54:946-52.

15. Catarino CB, Liu JYW, Liagkouras I, Gibbons VS, Labrum RW, Ellis R, et al. Dravet syndrome as epileptic encephalopathy: Evidence from long-term course and neuropathology. Brain. 2011;134(10):2982-3010.

16. Hattori J, Ouchida M, Ono J, Miyake S, Maniwa S, Mimaki N, et al. A Screening test for the prediction of Dravet syndrome before one year of age. Epilepsia. 2008;49(4):626-33.

17. Lagae L, Brambilla I, Mingorance A, Gibson E, Battersby A. Quality of life and comorbidities associated with Dravet syndrome severity: a multinational cohort survey. Dev Med Child Neurol. 2018;60(1):63-72.

18. Bremer A, Lossius MI, Nakken KO. Dravet syndrome - considerable delay in making the diagnosis. Acta Neurol Scand. 2012;125(5):359-62. 
19. Jansen FE, Sadleir LG, Harkin LA, Vadlamudi L, McMahon JM, Mulley JC, et al. Severe myoclonic epilepsy of infancy (Dravet syndrome): Recognition and diagnosis in adults. Neurology. 2006;67(12):2224-6.

20. Connolly MB. Dravet Syndrome: Diagnosis and Long-Term Course. Can J Neurol Sci. 2016;43:S3-8.

21. Garcelon N, Neuraz A, Salomon R, Faour H, Benoit V, Delapalme A, et al. A clinician friendly data warehouse oriented toward narrative reports: Dr. Warehouse. J Biomed Inform. 2018 Apr 1;80:52-63.

22. Neuraz A, Chouchana L, Malamut G, Le Beller C, Roche D, Beaune P, et al. Phenome-wide association studies on a quantitative trait: application to TPMT enzyme activity and thiopurine therapy in pharmacogenomics. PLoS Comput Biol. 2013;9(12):e1003405.

23. Denny JC, Ritchie MD, Basford MA, Pulley JM, Bastarache L, Brown-Gentry K, et al. PheWAS: Demonstrating the feasibility of a phenome-wide scan to discover gene-disease associations. Bioinformatics. 2010;26(9):1205-10.

24. Cetica V, Chiari S, Mei D, Parrini E, Grisotto L, Marini C, et al. Clinical and genetic factors predicting Dravet syndrome in infants with SCN1A mutations. Neurology. 2017;88(11):1037-44.

25. Dravet C, Guerrini R. Dravet Syndrome. John Libbey Eurotext; 2011.

26. Cross JH, Caraballo RH, Nabbout R, Vigevano F, Guerrini R, Lagae L. Dravet syndrome: Treatment options and management of prolonged seizures. Epilepsia. 2019;60(S3):S39-48.

27. Wirrell EC. Treatment of Dravet Syndrome. Can J Neurol Sci. 2016;43:S13-8.

28. Ohki T, Watanabe K, Negoro T, Aso K, Haga Y, Kasai K, et al. Severe myoclonic epilepsy in infancy: evolution of seizures. Seizure. 1997;6(3):219-24.

29. Gataullina S, Dulac O. From genotype to phenotype in Dravet disease. Seizure. 2017;44:58-64.

30. Nabbout R, Chemaly N, Chipaux M, Barcia G, Bouis C, Dubouch C, et al. Encephalopathy in children with Dravet syndrome is not a pure consequence of epilepsy. Orphanet J Rare Dis. 2013;8(1):1-8.

31. Verheyen K. Motor Development in children with Dravet syndrome. Dev Med Child Neurol. 2019;61:950-6.

32. Ragona F, Brazzo D, De Giorgi I, Morbi M, Freri E, Teutonico F, et al. Dravet syndrome: Early clinical manifestations and cognitive outcome in 37 Italian patients. Brain Dev. 2010;32:71-7.

33. Dalla Bernardina B, Capovilla G, Gattoni MB, Colamaria V, Bondavalli S, Bureau M. Epilepsie myoclonique grave de la premiere annee. Rev Electroencephalogr Neurophysiol Clin. 1982;12(1):21-5.

34. Verbeek N, Kasteleijn-Nolst Trenité D, Wassenaar M, van Campen J, Sonsma A, Gunning WB, et al. Photosensitivity in Dravet syndrome is under-recognized and related to prognosis. Clin Neurophysiol. 2017;128:323-30.

35. Wirrell EC, Laux L, Donner E, Jette N, Knupp K, Meskis MA, et al. Optimizing the Diagnosis and Management of Dravet Syndrome: Recommendations From a North American Consensus Panel. Pediatr Neurol. 2017;68:18-34.e3.

36. Wirrell EC, Laux L, Franz DN, Sullivan J, Saneto RP, Morse RP, et al. Stiripentol in Dravet syndrome: results of a retrospective U.S. study. Epilepsia. 2013;54(9):1595-604.

37. Nabbout R, Auvin S, Chiron C, Thiele E, Cross H, Scheffer IE, et al. Perception of impact of Dravet syndrome on children and caregivers in multiple countries: looking beyond seizures. Dev Med Child Neurol. 2019;61:1229-36. 
38. Shilo S, Rossman H, Segal E. Axes of a revolution: challenges and promises of big data in healthcare. Nat Med. 2020 Jan 1;26(1):29-38.

39. Castaneda C, Nalley K, Mannion C, Bhattacharyya P, Blake P, Pecora A, et al. Clinical decision support systems for improving diagnostic accuracy and achieving precision medicine. J Clin Bioinforma. 2015;5(1).

40. Fitipaldi H, McCarthy MI, Florez JC, Franks PW. A global overview of precision medicine in type 2 diabetes. Diabetes. 2018;67:1911-22.

41. Liang H, Tsui BY, Ni H, Valentim CCS, Baxter SL, Liu G, et al. Evaluation and accurate diagnoses of pediatric diseases using artificial intelligence. Nat Med. 2019;25(3):433-8.

42. Shmuely S, Sisodiya SM, Gunning WB, Sander JW, Thijs RD. Mortality in Dravet syndrome: A review. Epilepsy Behav. 2016;64(Pt A):69-74.

43. Kim Y, Bravo E, Thirnbeck CK, Smith-Mellecker LA, Kim SH, Gehlbach BK, et al. Severe peri-ictal respiratory dysfunction is common in Dravet syndrome. J Clin Invest. 2018;128(3):1141-53.

44. Hesdorffer DC, Shinnar S, Lewis D V., Moshé SL, Nordli DR, Pellock JM, et al. Design and phenomenology of the FEBSTAT study. Epilepsia. 2012 Sep;53(9):1471-80.

45. Vitaliti G, Castagno E, Ricceri F, Urbino A, Di Pianella AV, Lubrano R, et al. Epidemiology and diagnostic and therapeutic management of febrile seizures in the Italian pediatric emergency departments: A prospective observational study. Epilepsy Res. 2017;129:79-85.

\section{Tables}

Table 1. Comparison between concepts found in more than $10 \%$ of individuals of DS Cohort (left) and FS Cohort (right). $C U I=$ Concept Unique Identifiers. 


\begin{tabular}{|c|c|c|c|c|c|}
\hline \multirow{2}{*}{$\begin{array}{l}\text { UMLS CUI } \\
\text { Code }\end{array}$} & \multirow[t]{2}{*}{ Concept } & \multicolumn{2}{|l|}{ DS cohort } & \multicolumn{2}{|l|}{ FS cohort } \\
\hline & & $\begin{array}{l}\text { Found in } \\
\text { Individuals }\end{array}$ & $\begin{array}{l}\text { Frequency } \\
(>10 \%)\end{array}$ & $\begin{array}{l}\text { Found in } \\
\text { Individuals }\end{array}$ & $\begin{array}{l}\text { Frequency } \\
(>10 \%)\end{array}$ \\
\hline C0036572 & Seizures & 48 & $94 \%$ & 44 & $83 \%$ \\
\hline C0015967 & Fever & 43 & $84 \%$ & 48 & $91 \%$ \\
\hline C0014544 & Epilepsy & 42 & $82 \%$ & 35 & $66 \%$ \\
\hline C0751122 & Dravet Syndrome & 37 & $73 \%$ & & \\
\hline C0234972 & Convulsions & 31 & $61 \%$ & 40 & $75 \%$ \\
\hline C1419856 & SCN1A & 28 & $55 \%$ & & \\
\hline C0009952 & Febrile Seizures & 21 & $41 \%$ & 37 & $70 \%$ \\
\hline C0026827 & Hypotonia & 21 & $41 \%$ & 19 & $36 \%$ \\
\hline $\mathrm{C} 2825055$ & Recurrence & 21 & $41 \%$ & 30 & $57 \%$ \\
\hline C0234535 & Clonic & 17 & $33 \%$ & 9 & $17 \%$ \\
\hline C1705236 & Deviation & 17 & $33 \%$ & & \\
\hline C3809175 & $\begin{array}{l}\text { Prolonged } \\
\text { Seizure }\end{array}$ & 16 & $31 \%$ & 8 & $15 \%$ \\
\hline C2830004 & Drowsiness & 16 & $31 \%$ & 17 & $32 \%$ \\
\hline C0038220 & $\begin{array}{l}\text { Status } \\
\text { Epilepticus }\end{array}$ & 15 & $29 \%$ & 8 & $15 \%$ \\
\hline C0259972 & Ketogenic Diet & 13 & $25 \%$ & & \\
\hline C0235195 & Sedation & 13 & $25 \%$ & & \\
\hline C3887612 & $\begin{array}{l}\text { Psychomotor } \\
\text { Agitation }\end{array}$ & 12 & $24 \%$ & 7 & $13 \%$ \\
\hline C0009450 & Infection & 12 & $24 \%$ & 9 & $17 \%$ \\
\hline C0027066 & Myoclonia & 11 & $22 \%$ & & \\
\hline C1698630 & Virosis & 11 & $22 \%$ & 11 & $21 \%$ \\
\hline C0030193 & Pain & 10 & $20 \%$ & 6 & $11 \%$ \\
\hline C0013144 & Falling Asleep & 10 & $20 \%$ & 12 & $23 \%$ \\
\hline C0026837 & Hypertonus & 10 & $20 \%$ & 8 & $15 \%$ \\
\hline C0029877 & Otitis & 10 & $20 \%$ & 13 & $25 \%$ \\
\hline C0522336 & Rolling of eyes & 10 & $20 \%$ & 18 & $34 \%$ \\
\hline C0010200 & Cough & 10 & $20 \%$ & 9 & $17 \%$ \\
\hline
\end{tabular}




\begin{tabular}{|c|c|c|c|c|c|}
\hline C0004134 & Ataxia & 9 & $18 \%$ & & \\
\hline C0006271 & Bronchiolitis & 9 & $18 \%$ & 11 & $21 \%$ \\
\hline C0009443 & Rhinitis & 9 & $18 \%$ & 14 & $26 \%$ \\
\hline C0085639 & Fall & 8 & $16 \%$ & & \\
\hline C0424927 & Education & 8 & $16 \%$ & & \\
\hline C0024115 & Pneumonia & 8 & $16 \%$ & & \\
\hline C0684320 & Regression & 8 & $16 \%$ & & \\
\hline C0020517 & Allergies & 7 & $14 \%$ & & \\
\hline C0751495 & Focal Seizures & 7 & $14 \%$ & & \\
\hline C0015672 & Fatigue & 7 & $14 \%$ & 7 & $13 \%$ \\
\hline C0026205 & Myosis & 7 & $14 \%$ & & \\
\hline C0036973 & Shiverings & 7 & $14 \%$ & & \\
\hline C0035561 & Side & 6 & $12 \%$ & & \\
\hline C0031350 & Pharingitis & 6 & $12 \%$ & 8 & $15 \%$ \\
\hline C0424230 & $\begin{array}{l}\text { Psychomotor } \\
\text { Delay }\end{array}$ & 6 & $12 \%$ & & \\
\hline C0027441 & Nasopharyngitis & 6 & $12 \%$ & & \\
\hline C0549209 & Startle & 6 & $12 \%$ & & \\
\hline C0003123 & Anorexia & 5 & $10 \%$ & & \\
\hline C0034642 & Rales & 5 & $10 \%$ & & \\
\hline C0270844 & Tonic Seizures & 5 & $10 \%$ & 6 & $11 \%$ \\
\hline C0010520 & Cyanosis & 5 & $10 \%$ & 9 & $17 \%$ \\
\hline C0011991 & Diarrhea & 5 & $10 \%$ & & \\
\hline C0017160 & Gastroenteritis & 5 & $10 \%$ & & \\
\hline C0019209 & Hepatomegaly & 5 & $10 \%$ & & \\
\hline C0013384 & $\begin{array}{l}\text { Movement } \\
\text { Disorder }\end{array}$ & 5 & $10 \%$ & & \\
\hline C0013604 & Edema & 5 & $10 \%$ & & \\
\hline C0232483 & Reflux & 5 & $10 \%$ & & \\
\hline C0035203 & Respiration & 5 & $10 \%$ & & \\
\hline C0037763 & Spasms & 5 & $10 \%$ & & \\
\hline C1504405 & Pyramidal & 5 & $10 \%$ & & \\
\hline
\end{tabular}




\begin{tabular}{|llccc|}
\hline & Syndrome & & & \\
\hline C0008049 & Chickenpox & 5 & 7 & $13 \%$ \\
\hline C0596002 & Reflex & 19 & $36 \%$ \\
\hline C0271429 & $\begin{array}{l}\text { Acute Otitis } \\
\text { Media }\end{array}$ & 9 & $17 \%$ \\
\hline C0042963 & $\begin{array}{l}\text { Normal Pulse } \\
\text { Pressure }\end{array}$ & Vomiting & 8 & $15 \%$ \\
\hline C0034150 & Purpura & 8 & $15 \%$ \\
\hline C0494475 & $\begin{array}{l}\text { Tonic-clonic } \\
\text { seizures }\end{array}$ & 7 & $13 \%$ \\
\hline
\end{tabular}

Table 2. Phenome-wide comparison of DS Cohort and FS Cohort. CUI = Concept Unique Identif 


\begin{tabular}{|c|c|c|c|c|c|c|c|}
\hline $\begin{array}{l}\text { UMLS CUI } \\
\text { Code }\end{array}$ & Concept & $\begin{array}{l}\text { Found in } \\
\text { DS } \\
\text { individuals } \\
(\%)\end{array}$ & $\begin{array}{l}\text { Found in } \\
\text { FS } \\
\text { individuals } \\
(\%)\end{array}$ & $\begin{array}{l}\text { Not found } \\
\text { in DS } \\
\text { individuals } \\
(\%)\end{array}$ & $\begin{array}{l}\text { Not found } \\
\text { in } \mathrm{FS} \\
\text { individuals } \\
(\%)\end{array}$ & OR & $\begin{array}{l}p \\
\text { value }\end{array}$ \\
\hline C0751122 & $\begin{array}{l}\text { Dravet } \\
\text { Syndrome }\end{array}$ & $36(70,6)$ & $0(0)$ & $15(29,4)$ & $53(100)$ & 129,60 & 0,00 \\
\hline C1419856 & SCN1A & $28(54,9)$ & $0(0)$ & $23(45,1)$ & $53(100)$ & 65,74 & 0,00 \\
\hline C1705236 & Deviation & $17(33,3)$ & $4(7,5)$ & $34(66,7)$ & $49(92,5)$ & 6,37 & 0,00 \\
\hline C0259972 & Ketogenic Diet & $13(25,5)$ & $0(0)$ & $38(74,5)$ & $53(100)$ & 18,47 & 0,01 \\
\hline C0009952 & Febrile Seizures & $21(41,2)$ & $37(69,8)$ & $30(58,8)$ & $16(30,2)$ & 0,34 & 0,01 \\
\hline C0235195 & Sedation & $13(25,5)$ & $4(7,5)$ & $38(74,5)$ & $49(92,5)$ & 4,36 & 0,02 \\
\hline C0027066 & Myoclonia & $11(21,6)$ & $3(5,7)$ & $40(78,4)$ & $50(94,3)$ & 4,77 & 0,02 \\
\hline $\mathrm{C} 0004134$ & Ataxia & $9(17,6)$ & $1(1,9)$ & $42(82,4)$ & $52(98,1)$ & 11,57 & 0,02 \\
\hline C0024115 & Pneumonia & $8(15,7)$ & $0(0)$ & $43(84,3)$ & $53(100)$ & 10,05 & 0,03 \\
\hline C0684320 & Regression & $8(15,7)$ & $0(0)$ & $43(84,3)$ & $53(100)$ & 10,05 & 0,03 \\
\hline C0234535 & Clonic & $17(33,3)$ & $9(17)$ & $34(66,7)$ & $44(83)$ & 2,56 & 0,05 \\
\hline C0085639 & Fall & $8(15,7)$ & $2(3,8)$ & $43(84,3)$ & $51(96,2)$ & 4,93 & 0,05 \\
\hline C3809175 & $\begin{array}{l}\text { Prolonged } \\
\text { Seizure }\end{array}$ & $16(31,4)$ & $8(15,1)$ & $35(29,6)$ & $45(84,9)$ & 2,87 & 0,05 \\
\hline $\mathrm{C} 0014544$ & Epilepsy & $41(80,4)$ & $35(66)$ & $10(19,6)$ & $18(34)$ & 2,34 & 0,06 \\
\hline C0038220 & $\begin{array}{l}\text { Status } \\
\text { Epilepticus }\end{array}$ & $15(29,4)$ & $8(15,1)$ & $36(70,6)$ & $45(84,9)$ & 2,45 & 0,07 \\
\hline C0424230 & $\begin{array}{l}\text { Psychomotor } \\
\text { Delay }\end{array}$ & $6(11,8)$ & $0(0)$ & $45(88,2)$ & $53(100)$ & 7,20 & 0,07 \\
\hline C0549209 & Startle & $6(11,8)$ & $0(0)$ & $45(88,2)$ & $53(100)$ & 7,20 & 0,07 \\
\hline C0855324 & $\begin{array}{l}\text { Normal Pulse } \\
\text { Pressure }\end{array}$ & $2(3,9)$ & $8(15,1)$ & $49(96,1)$ & $52(98,1)$ & 0,24 & 0,08 \\
\hline C0026205 & Myosis & $7(13,7)$ & $2(3,8)$ & $44(86,3)$ & $51(96,2)$ & 4,22 & 0,08 \\
\hline C0036572 & Seizures & $47(92,9)$ & $44(83)$ & $4(7,8)$ & $9(17)$ & 2,94 & 0,08 \\
\hline C0271429 & $\begin{array}{l}\text { Acute Otitis } \\
\text { Media }\end{array}$ & $3(5,9)$ & $9(17)$ & $48(94,1)$ & $44(83)$ & 0,32 & 0,10 \\
\hline C0003123 & Anorexia & $5(9,8)$ & $0(0)$ & $46(90,2)$ & $53(100)$ & 5,87 & 0,11 \\
\hline C0013604 & Edema & $5(9,8)$ & $1(1,9)$ & $46(90,2)$ & $52(98,1)$ & 5,87 & 0,11 \\
\hline C0035203 & Respiration & $5(9,8)$ & $1(1,9)$ & $46(90,2)$ & $52(98,1)$ & 5,87 & 0,11 \\
\hline C0037763 & Spasms & $5(9,8)$ & $1(1,9)$ & $46(90,2)$ & $52(98,1)$ & 5,87 & 0,11 \\
\hline
\end{tabular}




\begin{tabular}{|c|c|c|c|c|c|c|c|}
\hline C0034150 & Purpura & $2(3,9)$ & $7(13,2)$ & $49(96,1)$ & $46(86,8)$ & 0,28 & 0,12 \\
\hline C0522336 & Rolling of eyes & $10(19,6)$ & $18(34)$ & $41(80,4)$ & $35(66)$ & 0,50 & 0,13 \\
\hline C0231218 & Malaise & $1(2)$ & $5(9,4)$ & $50(98)$ & $48(90,6)$ & 0,20 & 0,15 \\
\hline C0427008 & Stiffness & $1(2)$ & $5(9,4)$ & $50(98)$ & $48(90,6)$ & 0,20 & 0,15 \\
\hline C1336751 & Flat & $1(2)$ & $5(9,4)$ & $50(98)$ & $48(90,6)$ & 0,20 & 0,15 \\
\hline С3887612 & $\begin{array}{l}\text { Pyschomotor } \\
\text { Agitation }\end{array}$ & $12(23,5)$ & $7(13,2)$ & $39(76,5)$ & $46(86,8)$ & 2,11 & 0,15 \\
\hline C0042963 & Vomiting & $3(5,9)$ & $8(15,1)$ & $48(94,1)$ & $45(84,9)$ & 0,37 & 0,16 \\
\hline C0036973 & Shiverings & $7(13,7)$ & $3(5,7)$ & $44(86,3)$ & $50(94,3)$ & 2,76 & 0,16 \\
\hline C0751495 & Focal Seizures & $7(13,7)$ & $3(5,7)$ & $44(86,3)$ & $50(94,3)$ & 2,76 & 0,16 \\
\hline C2825055 & Recurrence & $21(41,2)$ & $30(56,6)$ & $30(58,8)$ & $23(43,4)$ & 0,58 & 0,17 \\
\hline C0013473 & $\begin{array}{l}\text { Eating } \\
\text { Disorders }\end{array}$ & $4(7,8)$ & $0(0)$ & $47(92,9)$ & $53(100)$ & 4,60 & 0,18 \\
\hline C0018989 & Hemiparesis & $4(7,8)$ & $1(1,9)$ & $47(92,9)$ & $52(98,1)$ & 4,60 & 0,18 \\
\hline C0020649 & Hypotension & $4(7,8)$ & $0(0)$ & $47(92,9)$ & $53(100)$ & 4,60 & 0,18 \\
\hline C0032290 & $\begin{array}{l}\text { Aspiration } \\
\text { Pneumonia }\end{array}$ & $4(7,8)$ & $0(0)$ & $47(92,9)$ & $53(100)$ & 4,60 & 0,18 \\
\hline C0037036 & Hypersalivation & $4(7,8)$ & $0(0)$ & $47(92,9)$ & $53(100)$ & 4,60 & 0,18 \\
\hline C0038450 & Stridor & $4(7,8)$ & $0(0)$ & $47(92,9)$ & $53(100)$ & 4,60 & 0,18 \\
\hline C0205721 & $\begin{array}{l}\text { Nosocomial } \\
\text { Infection }\end{array}$ & $4(7,8)$ & $1(1,9)$ & $47(92,9)$ & $52(98,1)$ & 4,60 & 0,18 \\
\hline C0333641 & Atrophy & $4(7,8)$ & $0(0)$ & $47(92,9)$ & $53(100)$ & 4,60 & 0,18 \\
\hline C0349506 & Photosensitivity & $4(7,8)$ & $0(0)$ & $47(92,9)$ & $53(100)$ & 4,60 & 0,18 \\
\hline C0428167 & $\mathrm{FiO} 2$ & $4(7,8)$ & $1(1,9)$ & $47(92,9)$ & $52(98,1)$ & 4,60 & 0,18 \\
\hline C0865850 & $\begin{array}{l}\text { Acute } \\
\text { Respiratory } \\
\text { Insufficiency }\end{array}$ & $4(7,8)$ & $0(0)$ & $47(92,9)$ & $53(100)$ & 4,60 & 0,18 \\
\hline C1504405 & $\begin{array}{l}\text { Pyramidal } \\
\text { Syndrome }\end{array}$ & $4(7,8)$ & $0(0)$ & $47(92,9)$ & $53(100)$ & 4,60 & 0,18 \\
\hline
\end{tabular}

Table 3. Comparison between concepts found in more than $10 \%$ individuals of DS Cohort who received the diagnosis/suspicion before (left) and after (right) the age of two years. CUI = Concept Unique Identifiers. 


\begin{tabular}{|c|c|c|c|c|c|}
\hline \multirow{2}{*}{$\begin{array}{l}\text { UMLS CUI } \\
\text { Code }\end{array}$} & \multirow[t]{2}{*}{ Concept } & \multicolumn{2}{|c|}{ DS cohort diag $<2$ years } & \multicolumn{2}{|c|}{ DS cohort diag $>2$ years } \\
\hline & & $\begin{array}{l}\text { Found in } \\
\text { Individuals }\end{array}$ & Frequency & $\begin{array}{l}\text { Found in } \\
\text { Individuals }\end{array}$ & Frequency \\
\hline C0751122 & Dravet Syndrome & 36 & $100 \%$ & & \\
\hline C0036572 & Seizures & 36 & $100 \%$ & 11 & $79 \%$ \\
\hline C0015967 & Fever & 34 & $94 \%$ & 8 & $57 \%$ \\
\hline C0014544 & Epilepsy & 33 & $92 \%$ & 8 & $57 \%$ \\
\hline C0234972 & Convulsions & 26 & $72 \%$ & 5 & $36 \%$ \\
\hline C1419856 & SCN1A & 22 & $61 \%$ & 6 & $43 \%$ \\
\hline C0026827 & Hypotonia & 17 & $47 \%$ & 4 & $29 \%$ \\
\hline C2825055 & Recurrence & 17 & $47 \%$ & 4 & $29 \%$ \\
\hline C0009952 & Febrile Seizures & 15 & $42 \%$ & 5 & $36 \%$ \\
\hline C3809175 & Prolonged Seizure & 15 & $42 \%$ & & \\
\hline $\mathrm{C} 0234535$ & Clonic & 14 & $39 \%$ & 3 & $21 \%$ \\
\hline C0038220 & Status Epilepticus & 13 & $36 \%$ & 2 & $14 \%$ \\
\hline C0596002 & Reflex & 13 & $36 \%$ & 2 & $14 \%$ \\
\hline C1705236 & Deviation & 12 & $33 \%$ & 5 & $36 \%$ \\
\hline C2830004 & Drowsiness & 12 & $33 \%$ & 4 & $29 \%$ \\
\hline C0259972 & Ketogenic Diet & 11 & $31 \%$ & 2 & $14 \%$ \\
\hline C0235195 & Sedation & 11 & $31 \%$ & 2 & $14 \%$ \\
\hline C1698630 & Virosis & 11 & $31 \%$ & & \\
\hline C3887612 & $\begin{array}{l}\text { Psychomotor } \\
\text { Agitation }\end{array}$ & 10 & $28 \%$ & 2 & $14 \%$ \\
\hline C0009450 & Infection & 10 & $28 \%$ & & \\
\hline C0027066 & Myoclonia & 10 & $28 \%$ & & \\
\hline C0004134 & Ataxia & 9 & $25 \%$ & & \\
\hline C0030193 & Pain & 9 & $25 \%$ & & \\
\hline C0013144 & Falling Asleep & 9 & $25 \%$ & & \\
\hline C0029877 & Otitis & 9 & $25 \%$ & & \\
\hline C0009443 & Rhinitis & 9 & $25 \%$ & & \\
\hline C0010200 & Cough & 9 & $25 \%$ & & \\
\hline
\end{tabular}




\begin{tabular}{|c|c|c|c|c|c|}
\hline C0424927 & Education & 8 & $22 \%$ & & \\
\hline C0522336 & Rolling of eyes & 8 & $22 \%$ & 2 & $14 \%$ \\
\hline C0020517 & Allergies & 7 & $19 \%$ & & \\
\hline C0006271 & Bronchiolitis & 7 & $19 \%$ & 2 & $14 \%$ \\
\hline C0015672 & Fatigue & 7 & $19 \%$ & & \\
\hline C0026837 & Hypertonus & 7 & $19 \%$ & 3 & $21 \%$ \\
\hline C0026205 & Myosis & 7 & $19 \%$ & & \\
\hline C0024115 & Pneumonia & 7 & $19 \%$ & & \\
\hline C0085639 & Fall & 6 & $17 \%$ & & \\
\hline C0494475 & $\begin{array}{l}\text { Tonic-clonic } \\
\text { seizures }\end{array}$ & 6 & $17 \%$ & & \\
\hline C0751495 & Focal Seizures & 6 & $17 \%$ & & \\
\hline C0031350 & Pharingitis & 6 & $17 \%$ & & \\
\hline C0424230 & Psychomotor Delay & 6 & $17 \%$ & & \\
\hline C0684320 & Regression & 6 & $17 \%$ & 2 & $14 \%$ \\
\hline C0549209 & Startle & 6 & $17 \%$ & & \\
\hline C0036973 & Shiverings & 6 & $17 \%$ & & \\
\hline C0003123 & Anorexia & 5 & $14 \%$ & & \\
\hline C0035561 & Side & 5 & $14 \%$ & & \\
\hline C0034642 & Rales & 5 & $14 \%$ & & \\
\hline C0013604 & Edema & 5 & $14 \%$ & & \\
\hline C0035203 & Respiration & 5 & $14 \%$ & & \\
\hline C0424230 & Psychomotor Delay & 5 & $14 \%$ & & \\
\hline C0008049 & Chickenpox & 5 & $14 \%$ & & \\
\hline C0004093 & Asthenia & 4 & $11 \%$ & & \\
\hline C0270844 & Tonic Seizures & 4 & $11 \%$ & & \\
\hline C0010520 & Cyanosis & 4 & $11 \%$ & & \\
\hline C0011991 & Diarrhea & 4 & $11 \%$ & & \\
\hline C0221725 & $\begin{array}{l}\text { Bronchial } \\
\text { Obstruction }\end{array}$ & 4 & $11 \%$ & & \\
\hline C0017160 & Gastroenteritis & 4 & $11 \%$ & & \\
\hline C0021400 & Flu & 4 & $11 \%$ & & \\
\hline
\end{tabular}

Page 19/21 


\begin{tabular}{|c|c|c|c|c|c|}
\hline C0037036 & Hypersalivation & 4 & $11 \%$ & & \\
\hline C0042769 & Viral Infection & 4 & $11 \%$ & & \\
\hline C0349506 & Photosensitivity & 4 & $11 \%$ & & \\
\hline C0032290 & $\begin{array}{l}\text { Aspiration } \\
\text { Pneumonia }\end{array}$ & 4 & $11 \%$ & & \\
\hline C1272641 & $\begin{array}{l}\text { Arterial Blood } \\
\text { Pressure }\end{array}$ & 4 & $11 \%$ & & \\
\hline C0027441 & Nasopharyngitis & 4 & $11 \%$ & 2 & $14 \%$ \\
\hline C0037763 & Spasms & 4 & $11 \%$ & & \\
\hline C0038450 & Stridor & 4 & $11 \%$ & & \\
\hline C1504405 & $\begin{array}{l}\text { Pyramidal } \\
\text { Syndrome }\end{array}$ & 4 & $11 \%$ & & \\
\hline C0018916 & Angiome & & & 2 & $14 \%$ \\
\hline C0085584 & Encephalopathy & & & 2 & $14 \%$ \\
\hline C0018989 & Hemiparesis & & & 2 & $14 \%$ \\
\hline C0018991 & Hemiplegia & & & 2 & $14 \%$ \\
\hline C0019209 & Hepatomegaly & & & 2 & $14 \%$ \\
\hline C0232483 & Reflux & & & 2 & $14 \%$ \\
\hline
\end{tabular}

\section{Figures}




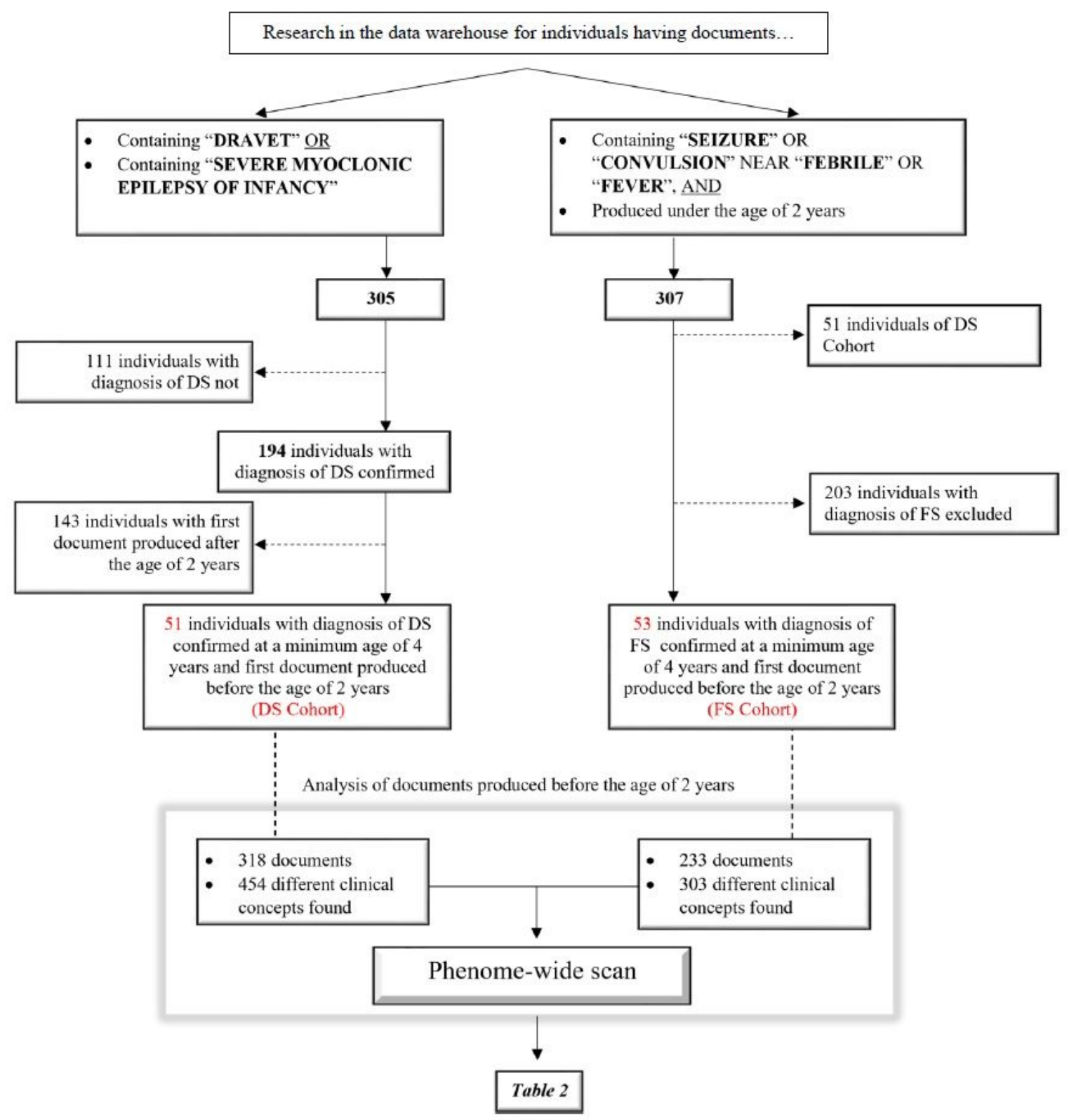

\section{Figure 1}

Flowchart of the selection procedures and comparison of the cohorts. 